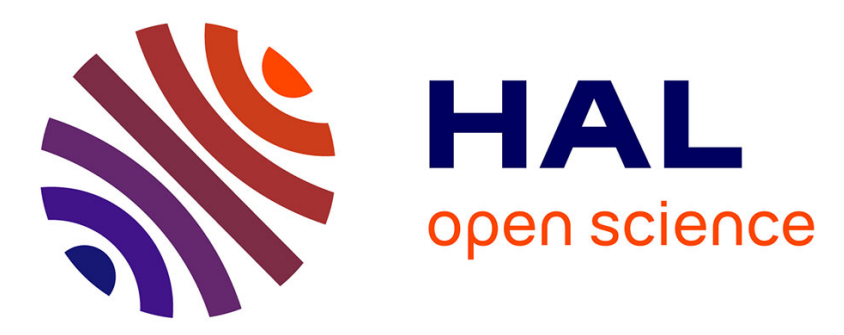

\title{
MIMO Hardware Simulator: Digital Block Design for 802.11ac Applications with TGn Channel Model Test
}

Bachir Habib, Gheorghe Zaharia, Ghaïs El Zein

\section{To cite this version:}

Bachir Habib, Gheorghe Zaharia, Ghaïs El Zein. MIMO Hardware Simulator: Digital Block Design for 802.11ac Applications with TGn Channel Model Test. IEEE VTC Spring 2012, May 2012, Yokohama, Japan. pp.1-5, 10.1109/VETECS.2012.6239922 . hal-00776612

\section{HAL Id: hal-00776612 \\ https://hal.science/hal-00776612}

Submitted on 15 Jan 2013

HAL is a multi-disciplinary open access archive for the deposit and dissemination of scientific research documents, whether they are published or not. The documents may come from teaching and research institutions in France or abroad, or from public or private research centers.
L'archive ouverte pluridisciplinaire HAL, est destinée au dépôt et à la diffusion de documents scientifiques de niveau recherche, publiés ou non, émanant des établissements d'enseignement et de recherche français ou étrangers, des laboratoires publics ou privés. 


\title{
MIMO Hardware Simulator: Digital Block Design for 802.11ac Applications with TGn Channel Model Test
}

\author{
Bachir Habib, Gheorghe Zaharia, Ghaïs El Zein \\ Institut d'Electronique et de Télécommunications de Rennes - IETR - UMR CNRS 6164 \\ 20 av. des Buttes de Coësmes, CS 70839 - 35708, Rennes cedex 7, France \\ bachir.habib@insa-rennes.fr
}

\begin{abstract}
This paper presents new frequency domain and time domain architectures for the digital block of a hardware simulator of MIMO propagation channels. This simulator can be used for 802.11ac applications. The hardware simulator facilitates the test and validation cycles by replicating channel artifacts in a controllable and repeatable laboratory environment, thus making it possible to ensure the same test conditions in order to compare the performance of various equipments. After the description of the general characteristics of the hardware simulator, the new architectures of the digital block are presented and designed on a Xilinx Virtex-IV FPGA. Their accuracy and latency are analyzed. TGn channel model $E$ tests are given in details. Lastly, results for all TGn channel models are presented.
\end{abstract}

Keywords-Hardware simulator; radio channel; MIMO; FPGA; TGn channel model

\section{INTRODUCTION}

Multiple-Input Multiple-Output (MIMO) systems make use of antenna arrays simultaneously at both transmitter and receiver to improve the channel capacity and the system performance. Because the transmitted electromagnetic waves interact with the propagation environment (indoor/outdoor), it is necessary to take into account the main propagation parameters for the design of the future communication systems.

Hardware simulators of mobile radio channel are very useful for the test and verification of wireless communication systems. These simulators are standalone units that provide the fading signal in the form of analog or digital samples [1], [2].

The current communication standards indicate a clear trend in industry toward supporting MIMO functionality. A support for higher order of antenna arrays will be required to enable higher channel capacity and system performance. In fact, several studies published recently present systems that reach a MIMO order of $8 \times 8$ and higher [3]. This is made possible by advances at all levels of the communication platform as, for example, the monolithic integration of antennas [4] and the design of the simulator platforms.

With the continuous increase of field programmable gate array (FPGA) capacity, entire baseband systems can be efficiently mapped onto faster FPGAs for more efficient prototyping, testing and verification. As shown in [5], the FPGAs provide the greatest flexibility in algorithm design and visibility of resource utilization. Also, they are ideal for rapid prototyping and research use such as testbed [6].

The simulator is reconfigurable with standards bandwidth not exceeding $100 \mathrm{MHz}$, which is the maximum for FPGA Virtex IV. However, in order to exceed $100 \mathrm{MHz}$ bandwidth, more performing FPGA as Virtex VI can be used [7]. The simulator is configured with the Long Term Evolution System (LTE) and Wireless Local Area Networks (WLAN) 802.11ac standards. The channel models used by the simulator can be obtained from standard channel models, as the TGn $802.11 \mathrm{n}$ [8], or from real measurements conducted with the MIMO channel sounder designed and realized at IETR [9]. Different architectures of antenna arrays can be used for outdoor and indoor measurements [10].

At IETR, several architectures of the digital block of a hardware simulator have been studied, in both time and frequency domains [11], [12]. Moreover, [13] presents a new method based on determining the parameters of a channel simulator by fitting the space time-frequency cross-correlation matrix of the simulation model to the estimated matrix of a real-world channel. This solution can be considered only as heuristic method because it shows that the error obtained can be important. Typically, wireless channels are commonly simulated using finite impulse response (FIR) filters, as in [12], [14] and [15]. Nowadays, different approaches have been widely used in filtering, such as distributed arithmetic (DA) and canonical signed digits (CSDs). However, for a hardware implementation, it is easier to use the FFT (Fast Fourier Transform) module to obtain an algebraic product. Thus, frequency architectures are presented, as in [12] and [14].

The previous considered frequency architectures in [12] operate correctly only for signals with a number of samples not exceeding the size of the FFT. However, in this paper, a new frequency domain architecture avoiding this limitation, and a new time domain architecture are both tested with TGn channel models, and a description in detail is given for TGn Model E.

The rest of this paper is organized as follows. Section II presents the new frequency and time domain architectures of the digital block. Section III shows the hardware implementation of the digital block for each architecture. Moreover, the accuracy of these two architectures is analyzed. Lastly, Section IV presents some concluding remarks. 


\section{HARDWARE SimUlator: PRINCIPLE, ARCHITECTURE AND OPERATION}

The simulator must reproduce the behavior of a MIMO propagation channel. The design of the RF blocks for UMTS (Universal Mobile Telecommunications System) was completed during a previous project [12]. It is able to accept input signals between -50 and $33 \mathrm{dBm}$. The objectives of PALMYRE II ${ }^{*}$ project concern the channel models and their hardware implementation into the MIMO simulator.

The bandwidth is between $1.5 \mathrm{MHz}$ and $20 \mathrm{MHz}$ for LTE, and $80 \mathrm{MHz}$ or $160 \mathrm{MHz}$ for 802.11 ac. However, The FPGA Virtex IV does not support bandwidths larger than $100 \mathrm{MHz}$. TGn channel models cover all scenarios for WLAN applications, and the duration of the impulse responses does not exceed $1.05 \mu \mathrm{s}$ for all TGn channel models. Thus, in this paper, tests are made with 802.11 ac standard with a considered bandwidth of $80 \mathrm{MHz}$.

\section{A. Channel Model}

TGn channel models [8] have a set of 6 profiles, labeled A to $\mathrm{F}$, which cover all the scenarios. Each model has a number of clusters. For example, model E, which is used for outdoor to indoor environment, has four clusters. Each cluster corresponds to specific tap delays, which overlaps each other in certain cases. Table I summaries the relative power of the impulse responses for TGn channel model $\mathrm{E}$ by taking the LOS (LineOf-Sight) impulse response as reference [8]. The relative powers of all impulse responses for all TGn channel models are presented in [8]. According to the standard and the bandwidth, the sampling frequency is $\mathrm{f}_{\mathrm{s}}=180 \mathrm{MHz}$ and $\mathrm{T}_{\mathrm{s}}=1 / \mathrm{f}_{\mathrm{s}}$.

TABLE I. RELATIVE POWER OF THE IMPUlse ReSPONSE FOR MODEL E

\begin{tabular}{|c|c|c|c|c|c|}
\hline $\begin{array}{c}\text { Tap } \\
\text { index }\end{array}$ & $\begin{array}{c}\text { Excess } \\
\text { delay }\left[\mathbf{n} \mathrm{T}_{\mathrm{s}}\right]\end{array}$ & $\begin{array}{c}\text { Relative } \\
\text { Power }[\mathbf{d B}]\end{array}$ & $\begin{array}{c}\text { Tap } \\
\text { index }\end{array}$ & $\begin{array}{c}\text { Excess } \\
\text { delay }[\mathbf{s}]\end{array}$ & $\begin{array}{c}\text { Relative } \\
\text { Power }[\mathbf{d B}]\end{array}$ \\
\hline $\mathbf{1}($ Ref) & 0 & -2.6 & $\mathbf{1 0}$ & $41 \mathrm{~T}_{\mathrm{s}}$ & -5.5 \\
\hline $\mathbf{2}$ & $2 \mathrm{~T}_{\mathrm{s}}$ & -3.0 & $\mathbf{1 1}$ & $50 \mathrm{~T}_{\mathrm{s}}$ & -7.6 \\
\hline $\mathbf{3}$ & $4 \mathrm{~T}_{\mathrm{s}}$ & -3.5 & $\mathbf{1 2}$ & $59 \mathrm{~T}_{\mathrm{s}}$ & -9.8 \\
\hline $\mathbf{4}$ & $5 \mathrm{~T}_{\mathrm{s}}$ & -3.9 & $\mathbf{1 3}$ & $68 \mathrm{~T}_{\mathrm{s}}$ & -12.0 \\
\hline $\mathbf{5}$ & $9 \mathrm{~T}_{\mathrm{s}}$ & -0.06 & $\mathbf{1 4}$ & $77 \mathrm{~T}_{\mathrm{s}}$ & -14.2 \\
\hline $\mathbf{6}$ & $14 \mathrm{~T}_{\mathrm{s}}$ & -1.2 & $\mathbf{1 5}$ & $88 \mathrm{~T}_{\mathrm{s}}$ & -15.3 \\
\hline $\mathbf{7}$ & $20 \mathrm{~T}_{\mathrm{s}}$ & -2.5 & $\mathbf{1 6}$ & $101 \mathrm{~T}_{\mathrm{s}}$ & -18.3 \\
\hline $\mathbf{8}$ & $25 \mathrm{~T}_{\mathrm{s}}$ & -3.8 & $\mathbf{1 7}$ & $115 \mathrm{~T}_{\mathrm{s}}$ & -20.7 \\
\hline $\mathbf{9}$ & $32 \mathrm{~T}_{\mathrm{s}}$ & -3.3 & $\mathbf{1 8}$ & $131 \mathrm{~T}_{\mathrm{s}}$ & -24.6 \\
\hline
\end{tabular}

The relative power of the first tap is different than zero because the impulse response is in NLON (Non-Line-OfSight). Fig. 1 presents the impulse response of TGn model E.

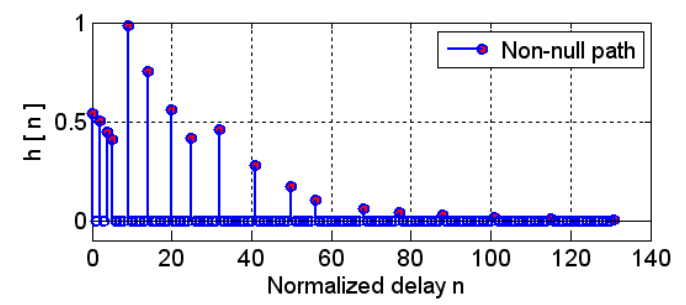

Figure 1. Channel impulse response of TGn channel model E.

The channel models used by the simulator can also be obtained from measurements by using a time domain MIMO channel sounder designed and realized at the IETR [9], as shown in Fig. 2.

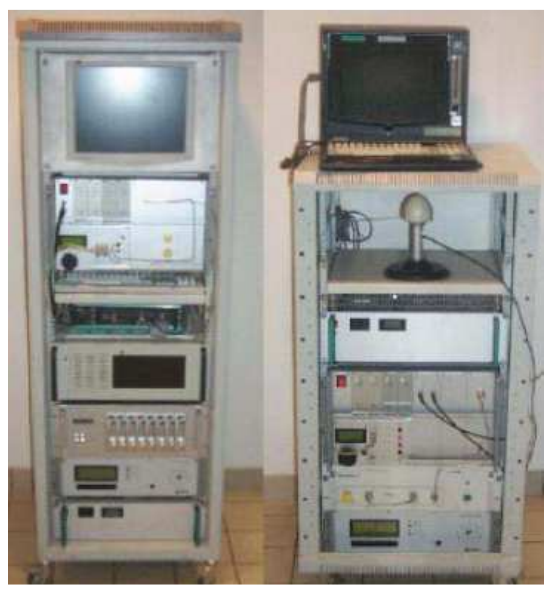

Figure 2. MIMO channel sounder: receiver and transmitter.

\section{B. Digital Block}

According to the considered propagation environments, Table II summarizes some useful parameters for WLAN 802.11 ac standard. The number of samples is:

$$
\mathrm{N}=\mathrm{W}_{\mathrm{t}} \mathrm{f}_{\mathrm{s}}
$$

where $W_{t}$ represents the width of the time window of the impulse response of the propagation channel.

TABLE II. SIMULATION PARAMETERS

\begin{tabular}{|c|c|c|c|c|}
\hline Type & Cell Size & $\mathbf{W}_{\text {t eff }}(\boldsymbol{\mu} \boldsymbol{s})$ & $\mathbf{N}$ & $\mathbf{W}_{\mathbf{t}}(\boldsymbol{\mu} \boldsymbol{s})$ \\
\hline Office & $40 \mathrm{~m}$ & 0.35 & 64 & 0.35 \\
Indoor & $50-150 \mathrm{~m}$ & 0.71 & 128 & 0.71 \\
Outdoor & $50-150 \mathrm{~m}$ & 1.16 & 256 & 1.42 \\
\hline
\end{tabular}

In order to have a suitable trade-off between complexity and latency, two solutions are considered: a time domain approach and a frequency domain approach. For indoor environments, $W_{t}$ is smaller than $1 \mu \mathrm{s}$. Therefore, the time domain approach is more suitable to use, because a FIR filter has, in spite of its relative complexity, much lower latency. However, the frequency approach has huge generated latency (more than $1 \mu \mathrm{s}$ ). $\mathrm{N}$ is the closest $2^{\mathrm{n}}$ value which is imposed by the FFT. Therefore, both approaches can be used according to the considered propagation environment.

A description of the architecture of the digital block for the "simple" frequency domain is presented in [12]. In this section, we present a new improved frequency domain architecture and a time domain architecture based on a FIR filter.

\section{1) New Frequency Domain Architecture}

The new frequency architecture for a SISO channel is presented in Fig. 3. This architecture has been verified and tested with Gaussian impulse response and a description is presented in [16]. It operates correctly for signals with a number of samples exceeding the size of the FFT module.

For TGn channel model E, $\mathrm{N}_{\text {eff }}=131$ samples. Thus, $\mathrm{N}=$ 128 samples (the last tap has a relative power of $-24.6 \mathrm{~dB}$, therefore it will be considered as zero). However, to test the new architecture, it is mandatory to extend each partial input of

* CPER PALMYRE - II Project supported by "Région Bretagne". 
$\mathrm{N}$ samples with a "tail" of $\mathrm{N}$ null samples, as in [16], to avoid a wrong result. Therefore, 256-FFT/IFFT modules are used.

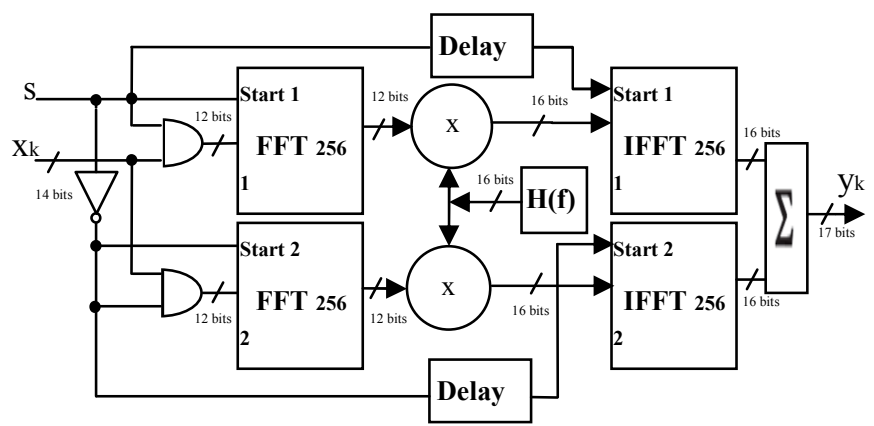

Figure 3. Frequency architecture of a SISO channel.

Due to the use of a 14-bit digital-to-analog convertor (DAC), the output of the final adder must be truncated. A simple solution is to keep the 14 most significant bits. This is a "brutal" truncation. However, a better solution is the sliding window truncation presented in Fig. 4 which uses the 14 most effective significant bits [11].

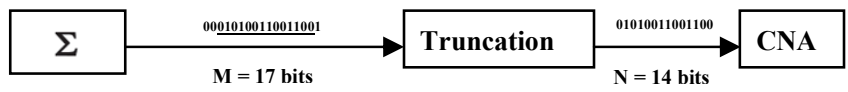

Figure 4. Sliding window truncation, from 17 to 14 bits.

\section{2) Time Domain Architecture}

Studies of the FIR filter with 64 points are presented in [11]. For TGn channel model E, the length of the FIR filter is $\mathrm{N}=131$. This model imposes the use of 18 multipliers. Thus, the output signal can be computed as:

$$
\mathrm{y}_{\mathrm{q}}(\mathrm{i})=\sum_{\mathrm{k}=1}^{18} \mathrm{~h}_{\mathrm{q}}\left(\mathrm{i}_{\mathrm{k}}\right) \mathrm{x}_{\mathrm{q}}\left(\mathrm{i}-\mathrm{i}_{\mathrm{k}}\right), \mathrm{i} \in \mathbf{N} \text {. }
$$

The index $\mathrm{q}$ suggests the use of quantified samples and $h_{q}\left(i_{k}\right)$ is the attenuation of the $k^{\text {th }}$ path with the delay $i_{k} T_{s}$. Fig. 5 presents the architecture of the FIR filter 131 with 18 non-null coefficients. This architecture uses series of impulse responses with a refresh frequency $f_{\text {ref }}$ depending on the coherence time of the channel, in order to simulate a time variant channel. Therefore, we have developed our own FIR filter instead of using Xilinx MAC FIR filter to make it possible to reload the FIR filter coefficients. $f_{\text {ref }}$ must be at least twice the maximum Doppler frequency.

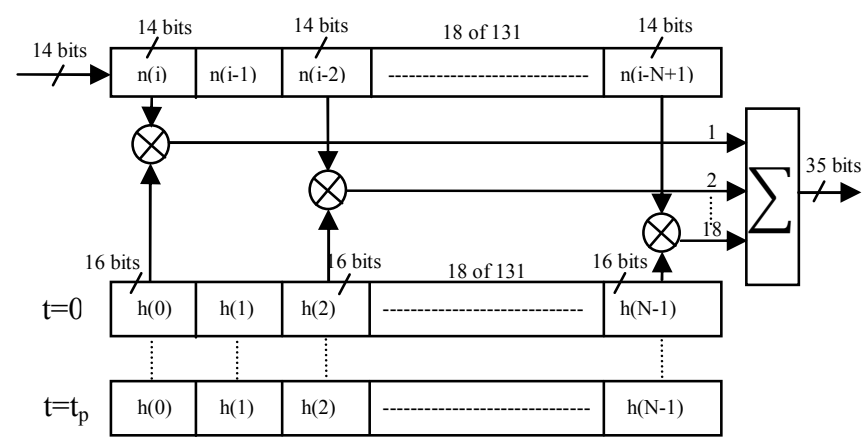

Figure 5. FIR 131 with 18 multipliers.

\section{IMPLEMENTATION}

In order to implement the hardware simulator, the adopted solution uses a prototyping platform (XtremeDSP Development Kit-IV for Virtex-4) from Xilinx [7], which is presented in Fig. 6 and described in [16].

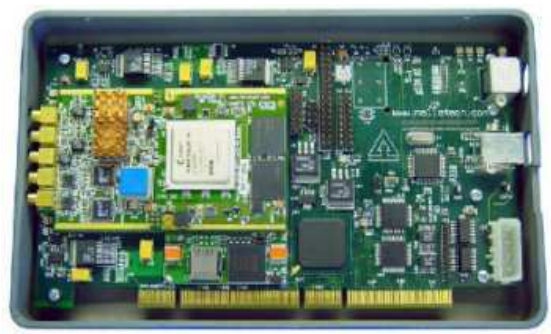

Figure 6. XtremeDSP Development board Kit-IV for Virtex-4.

The simulations and synthesis are made with Xilinx ISE [7] and ModelSim software [17].

\section{A. Implementation and Results of Frequency Architecture}

The V4-SX35 utilization summary for this architecture with FFT 256 and IFFT 256 blocks is given in Table III.

TABLE III. VIRTEX-4 SX35 UTILIZATION FOR 2 FFTS AND 2 IFFTS IN PING-PONG FREQUENCY ARCHITECTURE

\begin{tabular}{|l|l|l|}
\hline Number of slices & 4,084 out of 15,360 & $27 \%$ \\
\hline Number of bloc RAM & 18 out of 192 & $10 \%$ \\
\hline Number of DSP48s & 84 out of 192 & $45 \%$ \\
\hline
\end{tabular}

In order to determine the accuracy of the architecture, Gaussian input signal $\mathrm{x}(\mathrm{t})$ is considered long enough (more than $\mathrm{N}=256$ samples) to be used in streaming mode:

$$
\mathrm{x}(\mathrm{t})=\mathrm{x}_{\mathrm{m}} \mathrm{e}^{-\frac{\left(\mathrm{t}-\mathrm{m}_{\mathrm{x}}\right)^{2}}{2 \sigma^{2}}}, 0 \leq \mathrm{t} \leq 3 \mathrm{~W}_{\mathrm{t}}
$$

where $\mathrm{N}=256, \mathrm{~W}_{\mathrm{t}}=\mathrm{NT}_{\mathrm{s}}, \mathrm{m}_{\mathrm{x}}=3 \mathrm{~W}_{\mathrm{t}} / 4$ and $\sigma=\mathrm{m}_{\mathrm{x}} / 4$.

The A/D and D/A convertors of the development board have a full scale $\left[-\mathrm{V}_{\mathrm{m}}, \mathrm{V}_{\mathrm{m}}\right]$, with $\mathrm{V}_{\mathrm{m}}=1 \mathrm{~V}$. For the simulations we consider $x_{m}=V_{m} / 2$. The theoretical output signal is:

$$
y(t)=\sum_{k=1}^{18} h\left(i_{k}\right) x\left(t-i_{k} T_{s}\right)
$$

The relative error is computed for each output sample by:

$$
\varepsilon=\frac{Y_{\text {Xilinx }}-Y_{\text {theory }}}{Y_{\text {theory }}} .100[\%]
$$

where $Y_{\text {Xilinx }}$ and $Y_{\text {theory }}$ are vectors containing the samples of corresponding signals. The Signal-to-Noise Ratio (SNR) is:

$$
\operatorname{SNR}(\mathrm{i})=20 \log _{10}\left|\frac{\mathrm{Y}_{\text {theory }}(\mathrm{i})}{\mathrm{Y}_{\text {Xilinx }}(\mathrm{i})-\mathrm{Y}_{\text {theory }}(\mathrm{i})}\right|[\mathrm{dB}], \mathrm{i}=\overline{1,3 \mathrm{~N}+\mathrm{i}_{18}}
$$

Fig. 7 shows the theoretic signal and Xilinx signal at the output with their relative error for the new frequency architecture using TGn channel model $\mathrm{E}$, with $\mathrm{f}_{\mathrm{s}}=180 \mathrm{MHz}$. 

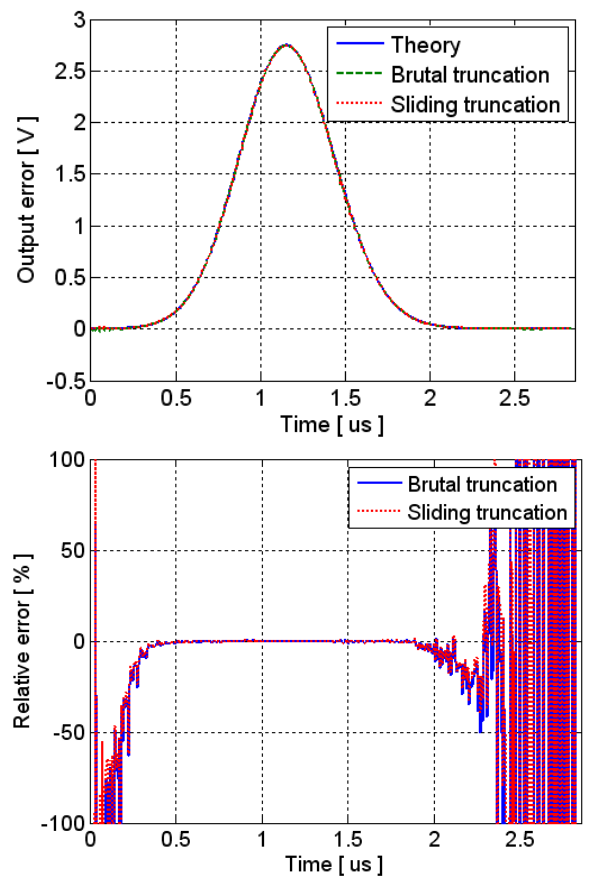

Figure 7. Theoretic and Xilinx output signals for the frequency architecture and the relative error, with TGn channel model E.

The values with brutal and sliding truncation are close because the signal before truncation is presented on 17 bits.

After the D/A convertor, the signal is limited to $\left[-\mathrm{V}_{\mathrm{m}}, \mathrm{V}_{\mathrm{m}}\right]$ with $\mathrm{V}_{\mathrm{m}}=1$. If $\mathrm{y}_{\max }>1 \mathrm{~V}$ as shown in Fig. 7, a reconfigurable analog amplifier placed after the DAC is mandatory to multiply the signal with $2^{\mathrm{k}_{0}}$, where $\mathrm{k}_{0}$ is the smallest integer verifying $\mathrm{y}_{\max }<2^{\mathrm{k}_{0}}$. The relative error is high only for small values of the output signal because the signal Gaussian test is close to 0 .

The global values of the relative error and of the SNR of the output signal after the final truncation are:

$$
\begin{gathered}
\varepsilon_{\mathrm{g}}=\frac{\|\mathrm{E}\|}{\left\|\mathrm{Y}_{\text {theory }}\right\|} .100[\%] \\
\mathrm{SNR}_{\mathrm{g}}=20 . \log 10 \frac{\left\|\mathrm{Y}_{\text {theory }}\right\|}{\|\mathrm{E}\|}[\mathrm{dB}]
\end{gathered}
$$

where $\mathrm{E}=\mathrm{Y}_{\mathrm{Xilinx}}-\mathrm{Y}_{\text {theory }}$ is the error vector. For a given vector $\mathrm{X}=\left[\mathrm{x}_{1}, \mathrm{x}_{2}, \ldots, \mathrm{x}_{\mathrm{L}}\right]$, its Euclidean norm $\|\mathrm{x}\|$ is:

$$
\|\mathrm{X}\|=\sqrt{\frac{1}{\mathrm{~L}} \sum_{\mathrm{k}=1}^{\mathrm{L}} \mathrm{x}_{\mathrm{k}}^{2}}
$$

Table IV shows the global values of the relative error and the global SNR between the theoretical and the Xilinx signal.

TABLE IV. COMPARISON OF THE GLOBAL ERROR AND SNR WITH FREQUENCY DOMAIN ARCHITECTURE

\begin{tabular}{|l|c|c|}
\hline \multicolumn{1}{|c|}{ Truncation effect } & Error (\%) & SNR (dB) \\
\hline Output without truncation & 0.2390 & 52.42 \\
\hline Output with sliding truncation & 0.2390 & 52.42 \\
\hline Output with brutal truncation & 0.2463 & 52.16 \\
\hline
\end{tabular}

\section{B. Implementation and Results of Temporal Architecture}

Table V shows the device utilization for a single FIR filter 131 for 18 selected positions for the channel impulse response which are considered as non-null, in one V4-SX35 after synthesis, mapping and route.

TABLE V. Simulation ReSUlts For FIR FiLteR

\begin{tabular}{|l|r|r|}
\hline Number of slices & 2,189 out of 15,360 & $14 \%$ \\
\hline Number of bloc RAM & 18 out of 192 & $9 \%$ \\
\hline Number of multipliers & 18 out of 192 & $9 \%$ \\
\hline
\end{tabular}

Fig. 8 presents the theoretic and Xilinx output signals using one FIR 131 with 18 coefficients considered as non-null and the relative error.
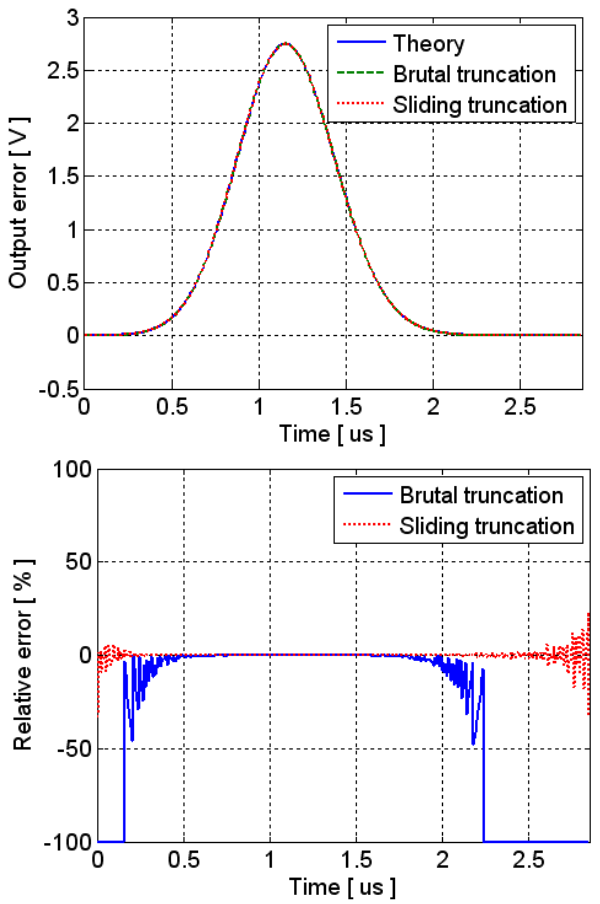

Figure 8. Theoretic and Xilinx output signals for the time domain architecture and the relative error, with TGn channel model E.

Table VI shows the global values of the relative error and the global SNR between the theoretical and the Xilinx signal.

TABLE VI. COMPARISON OF THE GLOBAL ERROR AND SNR WITH TIME DOMAIN ARCHITECTURE

\begin{tabular}{|l|c|c|}
\hline \multicolumn{1}{|c|}{ Truncation effect } & Error (\%) & SNR (dB) \\
\hline Output without truncation & 0.0050 & 86.10 \\
\hline Output with sliding truncation & 0.0120 & 78.43 \\
\hline Output with brutal truncation & 0.1699 & 55.38 \\
\hline
\end{tabular}

Before each operation, the 18 coefficients of the FIR filter are stored first in 1 shift register of length 18 via the USB port of the development board. Then, they are stored in the FPGA dual-port RAM.

\section{Result with all TGn Channel Models}

Table VII shows the global values of the relative error and SNR with sliding window truncation, and the occupation on the FPGA, for both architectures and for all TGn channel model B 
to F. As presented in [8], TGn model A should not be used for system performance comparisons.

TABLE VII. COMPARISON OF THE GLOBAL ERROR AND THE SNR FOR TGN CHANNEL MODELS

\begin{tabular}{|c|c|c|c|c|}
\hline \multirow{2}{*}{\begin{tabular}{|l|} 
Model B \\
Relative Error
\end{tabular}} & \multicolumn{2}{|c|}{ Frequency Architecture } & \multicolumn{2}{|c|}{ Time Architecture } \\
\hline & Error $(\%)$ & SNR (dB) & Error (\%) & SNR (dB) \\
\hline & 0.9666 & 40.25 & 0.0132 & 77.61 \\
\hline Slices (\%) & \multicolumn{2}{|c|}{15 (with FFTs 32) } & \multicolumn{2}{|c|}{ 11(with FIR 14) } \\
\hline \multicolumn{5}{|l|}{ Model C } \\
\hline \multirow[t]{2}{*}{ Relative Error } & Error $(\%)$ & SNR (dB) & Error (\%) & SNR (dB) \\
\hline & 0.4121 & 47.69 & 0.0109 & 79.24 \\
\hline Slices (\%) & \multicolumn{2}{|c|}{22 (with FFTs 128) } & \multicolumn{2}{|c|}{ 12(with FIR 36) } \\
\hline \multicolumn{5}{|l|}{ Model D } \\
\hline \multirow[t]{2}{*}{ Relative Error } & Error (\%) & SNR (dB) & Error (\%) & $\mathrm{SNR}(\mathrm{dB})$ \\
\hline & 0.2406 & 52.36 & 0.0106 & 79.45 \\
\hline Slices (\%) & \multicolumn{2}{|c|}{27 (with FFTs 256) } & \multicolumn{2}{|c|}{ 14(with FIR 70) } \\
\hline \multicolumn{5}{|l|}{ Model E } \\
\hline \multirow[t]{2}{*}{ Relative Error } & Error (\%) & SNR (dB) & Error (\%) & SNR (dB) \\
\hline & 0.2390 & 52.42 & 0.0120 & 78.43 \\
\hline Slices (\%) & \multicolumn{2}{|c|}{27 (with FFTs 256) } & \multicolumn{2}{|c|}{ 14(with FIR 131) } \\
\hline \multicolumn{5}{|l|}{ Model F } \\
\hline \multirow[t]{2}{*}{ Relative Error } & Error (\%) & SNR (dB) & Error $(\%)$ & SNR (dB) \\
\hline & 0.1714 & 55.31 & 0.0110 & 79.18 \\
\hline Slices (\%) & \multicolumn{2}{|c|}{35 (with FFTs 512) } & \multicolumn{2}{|c|}{ 14(with FIR 189) } \\
\hline
\end{tabular}

\section{Frequency and Time Architectures according to the Propagation Environment}

We compare the time domain architecture with the new frequency domain architecture. According to Table VII, three points resume the comparison: the precision, the occupation on the FPGA and the latency.

With sliding truncation, the relative error do not exceed 1 $\%$ (for the worst case, with TGn model B), which is sufficient for the test. However, the time domain architecture presents high precision.

In terms of occupation of slices on the FPGA Virtex IV, the maximum value for the time domain architecture is $14 \%$ in contrast with the occupation of the frequency domain architecture which vary between $15 \%$ and $35 \%$. Thus, the time domain architecture presents another advantage which allows the implementation of 6 SISO channels with model D, E and F. Therefore, MIMO $3 \times 2$ system can be used and which operates via $18 \times 6=108$ multipliers and producing an occupation of $84 \%$ of slices on the FPGA. With model B and $\mathrm{C}$, it is possible to implement 8 SISO channels.

In term of latency, the time domain architecture presents another point of advantage by generating a latency of $125 \mathrm{~ns}$. However, the new frequency architecture generates $63 \mu \mathrm{s}$.

Therefore, the time domain architecture is more efficient to use, especially for MIMO systems. However, the use of more performing FPGAs as Virtex 6 is mandatory to solve the occupation problem for the new frequency domain architecture. It will provide the use of many SISO channels and be able to test a MIMO system.

\section{CONCLUSION}

After a comparative study, in order to reduce occupation on the FPGA, the error and the latency of the digital block, the time domain architecture present the best solution for indoor environments, which has been tested in this paper with TGn channel model.

Nowadays, we test a configuration which requires 3 XtremeDSP Development Kit-IV. More measurement campaigns will be carried out with the MIMO channel sounder realized by IETR, for various types of environments (indoor, outdoor). More tests will be done by using a time-varying channel. Thus, the architectures will be completed to obtain a "dynamic" system. A Graphical User Interface will be designed to allow the user to reconfigure the channel parameters. The final objective is to obtain realistic and reliable impulse responses of the MIMO channel in order to supply the digital block of the hardware simulator.

\section{REFERENCES}

[1] Wireless Channel Emulator, Spirent Communications, 2006

[2] Baseband Fading Simulator ABFS, Reduced costs through baseband simulation, Rohde \& Schwarz, 1999.

[3] A. S. Behbahani, R. Merched, and A. Eltawil, "Optimizations of a MIMO relay network," IEEE, vol. 56, no. 10, pp. 5062-5073, Oct. 2008.

[4] B. A. Cetiner, E. Sengul, E. Akay, and E. Ayanoglu, "A MIMO system with multifunctional reconfigurable antennas," IEEE Antennas Wireless Propag. Lett., vol. 5, no. 1, pp. 463-466, Dec. 2006.

[5] P. Murphy, F. Lou, A. Sabharwal, P. Frantz, "An FPGA Based Rapid Prototyping Platform for MIMO Systems", Asilomar Conf. on Signals, Systems and Computers, ACSSC, vol. 1, pp. 900-904, 9-12 Nov. 2003.

[6] P. Murphy, F. Lou, J. P. Frantz, "A hardware testbed for the implementation and evaluation of MIMO algorithms", Conf. on Mobile and Wireless Communications Networks, Singapore, 27-29 Oct. 2003.

[7] "Xilinx: FPGA, CPLD and EPP solutions", www.xilinx.com.

[8] V. Erceg et al., "TGn Channel Models", IEEE 802.11- 03/940r4, May $10,2004$.

[9] G. El Zein, R. Cosquer, J. Guillet, H. Farhat, F. Sagnard, "Characterization and modeling of the MIMO propagation channel: an overview" European Conference on Wireless Technology, ECWT, 2005.

[10] H. Farhat, R. Cosquer, G. El Zein, "On MIMO channel characterization for future wireless communication systems", 4G Mobile \& Wireless Comm.Tech., River Publishers, Aalborg, Denmark, 2008, pp. 225-233.

[11] S. Picol, G. Zaharia, D. Houzet and G. El Zein, "Hardware simulator for MIMO radio channels: Design and features of the digital block", Proc. of IEEE VTC-Fall 2008, 21-24 Sept. 2008, Calgary, Canada.

[12] S. Picol-Williamson, G. Zaharia, G. El Zein, "Design of the digital block of a hardware simulator for MIMO radio channels", IEEE PIMRC, Helsinki, Finland, 2006.

[13] D. Umansky, M. Patzold, "Design of Measurement-Based Stochastic Wideband MIMO Channel Simulators", IEEE Globecom 2009, Honolulu, Hawai, 30 Nov. - 4 Dec. 2009.

[14] H. Eslami, S.V. Tran and A.M. Eltawil, "Design and implementation of a scalable channel Emulator for wideband MIMO systems", IEEE Trans. on Vehicular Technology, vol. 58, no. 9, Nov. 2009, pp. 4698-4708.

[15] S. Fouladi Fard, A. Alimohammad, B. Cockburn, C. Schlegel, "A single FPGA filter-based multipath fading emulator", VTC-Fall, Canada, 2009.

[16] B. Habib, G. Zaharia and G. El Zein, "Improved Frequency Domain Architecture for the Digital Block of a Hardware Simulator for MIMO Radio Channels", IEEE 978-1-61284-943-0, ISSCS June 2011.

[17] ModelSim - Advanced Simulation and Debugging, http://model.com. 